\title{
The cardiac surgeon as electrophysiologist
}

\author{
John M. Stulak, MD, and Hartzell V. Schaff, MD,
}

\author{
From the Division of Cardiovascular Surgery, Mayo Clinic College of Medicine, Rochester, Minn. \\ Disclosures: Authors have nothing to disclose with regard to commercial support. \\ Received for publication Sept 17, 2015; accepted for publication Sept 23, 2015; available ahead of print \\ Oct 26, 2015. \\ Address for reprints: John M. Stulak, MD, Mayo Clinic College of Medicine, 200 First St SW, Rochester, MN \\ 55905 (E-mail: stulak.john@mayo.edu). \\ J Thorac Cardiovasc Surg 2016;151:298-9 \\ 0022-5223/\$36.00 \\ Copyright (c) 2016 by The American Association for Thoracic Surgery \\ http://dx.doi.org/10.1016/j.jtcvs.2015.09.098
}

All cardiac surgeons encounter atrial fibrillation (AF) in clinical practice. Indeed, $20 \%$ to $40 \%$ of cardiac surgical patients will have transient atrial fibrillation in the early postoperative period, and the arrhythmia can prolong hospitalization and place the patient at increased risk for stroke and for bleeding complications from anticoagulation. Further, atrial fibrillation is a common finding in patients with structural heart disease being seen for valve repair or replacement and intracardiac repair. Combining some form of surgical ablation of atrial fibrillation with other cardiac procedures has become commonplace. So what are the issues in patient management?

It can be argued that no surgical procedure was planned, analyzed, and evaluated more rigorously than the Cox-maze procedure, and since its inception the Cox-maze III procedure has served as the benchmark for the surgical treatment of atrial fibrillation. ${ }^{1-3}$ Evaluation of outcomes of this procedure was predictable and consistent because of the standardized surgical technique and absolute guarantee of transmural lesions. Despite this, widespread adoption of the procedure was hindered mainly by its complexity, and in the current era the Cox-maze III procedure has largely become a historical operation. Various ablative energy sources and alternate lesion sets have become available to simplify the procedure and offer minimally invasive and off-pump approaches. ${ }^{4}$ As a predictable and inevitable consequence, evaluation of rhythm outcomes has become extremely challenging and plagued by heterogeneity, and disagreement now exists regarding the optimal approach. Furthermore, although new techniques have been aimed at delivering lesions more readily, they are doing so much less reliably, especially when transmurality is considered. Consensus statements do currently exist providing a framework to standardize the practice of surgical AF ablation and reporting of outcomes, ${ }^{5,6}$ but despite these, the literature continues to highlight lack of uniformity in multiple aspects of the practice.

The literature is replete with series documenting safety and effectiveness of surgical AF ablation, as defined by freedom from AF; however, the additional goals of reducing risk of

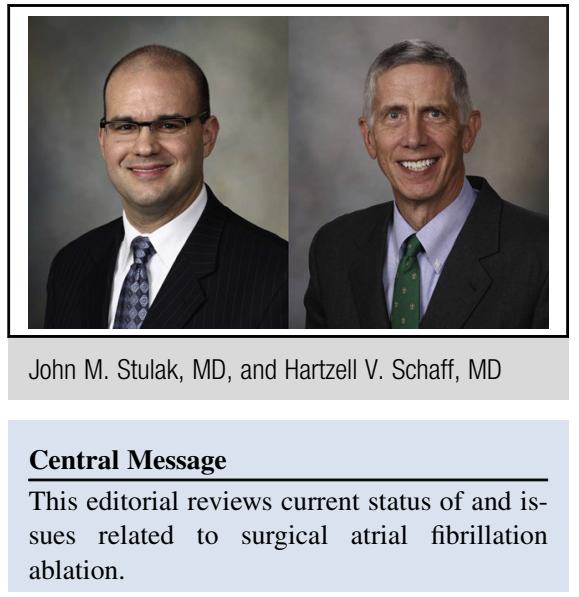

See Article page 391

See Editorial Commentary page 399.

thromboembolic events and improved quality of life often go unreported. We believe that all these variables are important in assessing the success of surgery for AF. Authors of series published on this topic call for more prospective, randomized trials to clarify the issues in question, but unfortunately the most recent trial conducted, that of Gillinov and colleagues, ${ }^{7}$ was compromised by modest goals, heterogeneous patient population and techniques, and admittedly, by being underpowered to analyze true clinical benefit. Although likely not altering clinical practice to a significant degree and leaving many issues unclarified, the authors later stated that it served to reaffirm that ablation has rhythm benefit while not increasing morbidity. ${ }^{8}$ Despite the study's shortcomings, arguably its greatest value lay in serving as an example that more of the kind are needed to address the confusion currently demonstrated in the literature.

It is interesting to note that concomitant surgical ablation of AF is performed in only $60 \%$ of patients with AF undergoing mitral valve operations, ${ }^{9}$ and one wonders whether lack of clarity regarding goals, energy source, or lesion set is contributing to this disparity. Some may view AF as an innocuous accompanying feature of valve disease, but its risks not only of stroke and heart failure but of longterm poor functional outcome should be appreciated. ${ }^{10}$ Whereas concomitant AF ablation during valve surgery is known to confer higher AF freedom than valve surgery alone, we believe that enhancing the clinical "success" has lain in selecting patients who might benefit most, which 
primarily includes patients who have limiting symptoms from their arrhythmia. There are additional subsets of patients in whom chronic anticoagulation could be avoided if sinus rhythm were to be achieved postoperatively.

A review of current practices in postoperative management of patients after surgical AF ablation also exposes uncertainty in approach to these patients. Prophylactic antiarrhythmic treatment after surgical AF ablation is controversial, and its utility in reducing early risk of recurrent $\mathrm{AF}$ has only been recently addressed. New prospective, randomized data have been helpful in clarifying this issue by demonstrating findings consistent with results seen after catheter ablation favoring the use of prophylactic class I or III antiarrhythmics after surgical AF ablation.

The monitoring of rhythm and reporting of success remain additional areas that pose challenges to our assessment of success and detection of recurrence. The optimal monitoring modality is still not known, with electrocardiography and Holter monitoring both advocated in some regard. Intuitively, more intensive rhythm monitoring after surgical ablation of AF seems more likely to detect AF recurrence. Whereas intermittent monitoring has been reported to miss recurrent AF episodes and overestimate success ${ }^{11}$ more continuous and in-depth monitoring many compromise patient compliance. From personal experience, we observed a high concordance rate between the modalities, and Holter monitoring does not add significant clinical value.

The movement away from standardized definitions, techniques, and follow-up evaluation will continue to result unavoidably in difficulty assessing outcomes. If any energy source or lesion set were to be truly demonstrated as superior, then widespread adoption would follow. We do not observe this trend, as techniques, tools, and approaches continue to evolve. This continued "search" for the most effective approach is multifactorial, but it is reassuring that the inclusion of these procedures continue to be safe and, although not as effective as once observed and reported by Cox, provide some additional measure of arrhythmia control.

\section{References}

1. Cox J, Schuessler RB, D'Agostino HJ Jr, Stone CM, Chang BC, Cain ME, et al. The surgical treatment of atrial fibrillation. III. Development of a definitive surgical procedure. J Thorac Cardiovasc Surg. 1991;101:569-83.

2. Cox JL, Boineau JP, Schuessler RB, Kater KM, Lappas DG. Five-year experience with the maze procedure for atrial fibrillation. Ann Thorac Surg. 1993;56: 814-23; discussion 823-4.

3. Stulak JM, Sundt TM III, Dearani JA, Daly RC, Orsulak TA, Schaff HV. Ten-year experience with the Cox-maze procedure for atrial fibrillation: how do we define success? Ann Thorac Surg. 2007;83:1319-24.

4. Edgerton ZJ, Edgerton JR. History of surgery for atrial fibrillation. Heart Rhythm. 2009;6(12 Suppl):S1-4.

5. Shemin RJ, Cox JL, Gillinov AM, Blackstone EH, Bridges CR, Workforce on Evidence-Based Surgery of the Society of Thoracic Surgeons. Guidelines for reporting data and outcomes for the surgical treatment of atrial fibrillation. Ann Thorac Surg. 2007;83:1225-30.

6. Calkins H, Brugada J, Packer DL, Cappato R, Chen SA, Crijns HJ, et al. European Heart Rhythm Association (EHRA); European Cardiac Arrhythmia Society (ECAS); American College of Cardiology (ACC); American Heart Association (AHA); Society of Thoracic Surgeons (STS). HRS/EHRA/ECAS expert consensus statement on catheter and surgical ablation of atrial fibrillation: recommendations for personnel, policy, procedures, and follow-up. A report of the Heart Rhythm Society (HRS) task force on catheter and surgical ablation of atrial fibrillation. Heart Rhythm. 2007;4:816-61.

7. Gillinov AM, Gelijns AC, Parides MK, DeRose JJ Jr, Moskowitz AJ, Voisine P, et al; CTSN Investigators. Surgical ablation of atrial fibrillation during mitral valve surgery. N Engl J Med. 2015;372:1399-409.

8. Gillinov M, Moskowitz AJ, Argenziano M. Surgical ablation for atrial fibrillation [letter]. N Engl J Med. 2015;373:484.

9. Schaff HV. Surgical ablation of atrial fibrillation — when, why, and how? N Engl J Med. 2015;372:1465-517.

10. Practice parameter: stroke prevention in patients with nonvalvular atrial fibrillation. Report of the quality standards subcommittee of the American Academy of Neurology. Neurology. 1998;51:671-3.

11. Ad N, Henry L, Hunt S, Barnett S, Stone L. The Cox-Maze III procedure success rate: comparison by electrocardiogram, 24-hour Holter monitoring and longterm monitoring. Ann Thorac Surg. 2009;88:101-5. 